\title{
La interpretación del patrimonio en el medio rural. ¿Y ahora qué?
}

En octubre del año pasado, se celebraba en Tenerife el $8 .^{\circ}$ Seminario sobre senderismo temático, valorización del patrimonio y desarrollo local. Entre los participantes, la autora de este texto presentaba una reflexión final bajo el título "Recursos para la orientación e interpretación del patrimonio en el entorno rural. Criterios y objetivos, diseños y usos, beneficios y abusos... ¿Y ahora qué?" Recogemos aquí algunas de las ideas que Victoria Batista planteó desde la consideración del momento actual de crisis económica como punto de inflexión para encontrar soluciones, oportunidades y valores a poner en relieve.

M. ${ }^{a}$ Victoria Batista Pérez | Facultad de Bellas Artes, Universidad de La Laguna

URL de la contribución <www.iaph.es/revistaph/index.php/revistaph/article/view/3391>

Partimos de un análisis de los recursos para la señalización e información de senderos, itinerarios culturales e interpretación del patrimonio en el entorno rural. Caracterizar criterios y métodos, tipos de recursos, diseños y contenidos, bondades e inconvenientes ha sido nuestro objetivo.

Haciendo una revisión en el tiempo, a lo mejor ahora es el momento de plantear una reflexión, ante un horizonte de crisis económica que está frenando sustancialmente la financiación de proyectos, en lo cual podemos encontrar incluso ventajas y proponer alternativas.

En las últimas décadas las tendencias de musealización del patrimonio in situ han tenido sus más y sus menos. Distintos programas de desarrollo rural han financiado una gran variedad de infraestructuras y equipamientos promovidos por entidades de gobierno, que en muchos casos se lo podrían haber ahorrado y, en ocasiones, ha sido contraproducente. Sin embargo, se ha invertido menos en crear tejidos de desarrollo sostenible y de generación de empleo, basados en los oficios de arte, artesanías y quehaceres de los lugareños. Nos encontramos con casos de creación de centros de interpretación o museos, más bien mausoleos, con una visión de lo rural como algo del pasado, lo cual ya está limitando el futuro de las medianías.

La crisis económica actual viene de la mano de una crisis de valores. La eliminación o la desvalorización del patrimonio local, planteada desde la explotación econó- mica de estas pasadas décadas, nos hace ver ahora que era necesaria su conservación para las futuras generaciones. El mal entendido desarrollo ha traído consigo el abandono del campo y la infravaloración de su patrimonio. ¿Es tarde para su recuperación?

Examinamos algunos ejemplos que podemos escuchar en las noticias de los informativos televisivos:

- "Se han acabado las subvenciones para la desalinización de las aguas en Canarias, los pozos abandonados están siendo recuperados para la extracción del agua". Éste sería un ejemplo de puesta en valor de las infraestructuras tradicionales para la extracción del agua (patrimonio tangible) motivado por su interés y necesidad de uso.

- "La gastronomía tradicional (patrimonio intangible) vuelve a la mesa. Para procurar el ahorro se recuperan los platos de cuchara, las legumbres..." y de camino es bueno para la salud: la proteína animal produce enfermedades cardiovasculares, en tiempos de carestía esto no pasa.

Así pues, como se dice en estos casos: "No hay mal que por bien no venga".

Poner más énfasis en el patrimonio intangible y humano podría ser el quid de la cuestión. Podemos entre todos encontrar múltiples opciones y posibilidades, considerar los modelos de actuación positiva existentes. Proponer 


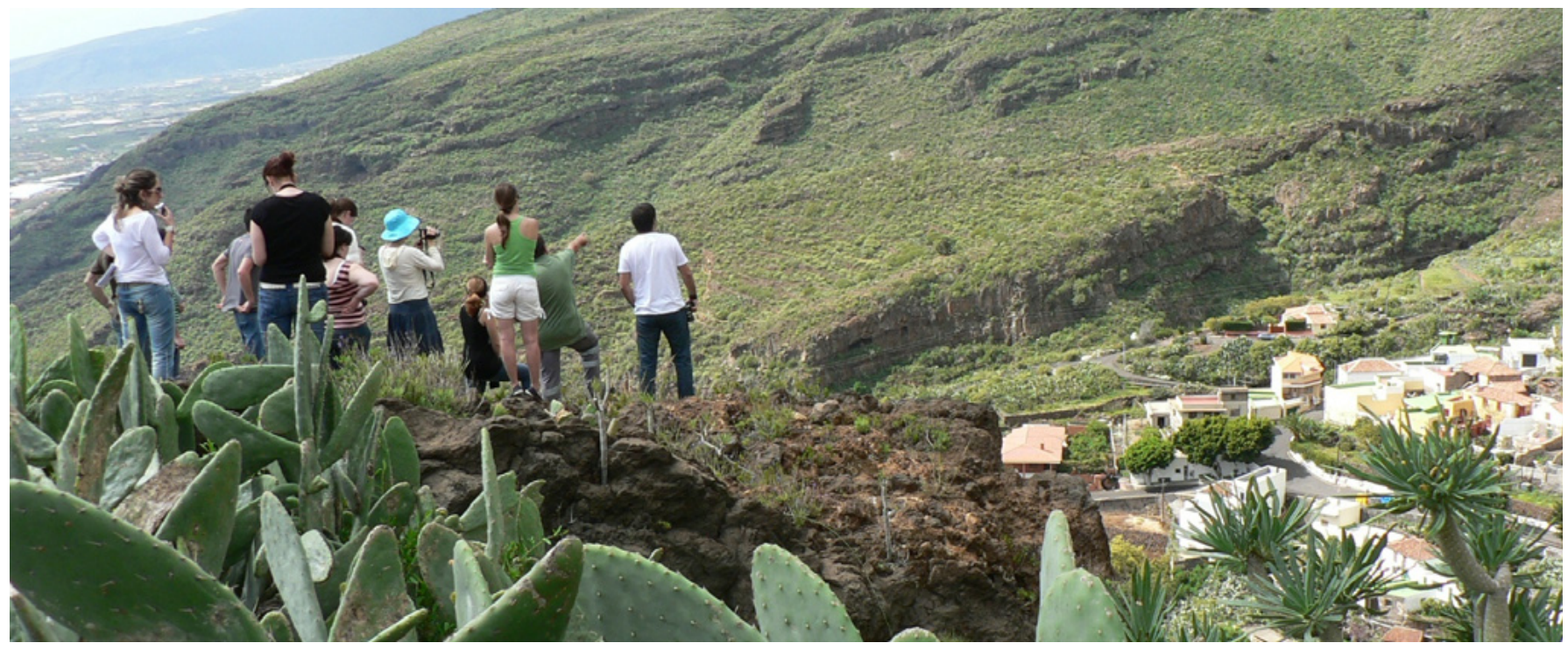

Planificación integral de los recursos patrimoniales. Estudios de campo para el proyecto expositivo del centro rural de Candelaria, con la participación de alumnado de museografía. Facultad de Bellas Artes, Universidad de La Laguna (Tenerife) | foto Noelia Zoe García

claves de acción con la participación activa del habitante que promuevan el desarrollo local y que inviten al visitante a vivenciar y a sentir el mundo rural, a disfrutarlo y a conocer la idiosincrasia del lugar.

La puesta en valor del patrimonio ha de pasar por una planificación integral, objetivos claros y el uso de los adecuados recursos en cada caso, con respeto al entorno, minimizando el impacto ambiental. Lograr un equilibrio entre la preservación y la difusión del patrimonio rural, sin abusar de equipamientos materiales de señalización e información que alteren el equilibrio con el paisaje.

A modo de recapitulación y a tenor del panorama de crisis: una sociedad menos paternalista, menos dependiente de los poderes fácticos y políticos, supone un acto de responsabilidad y de protagonismo de la propia comunidad en su devenir y en lo que concierne a la búsqueda de referentes, lo cual es una oportunidad para reafirmar los valores, el diálogo, la memoria compartida.

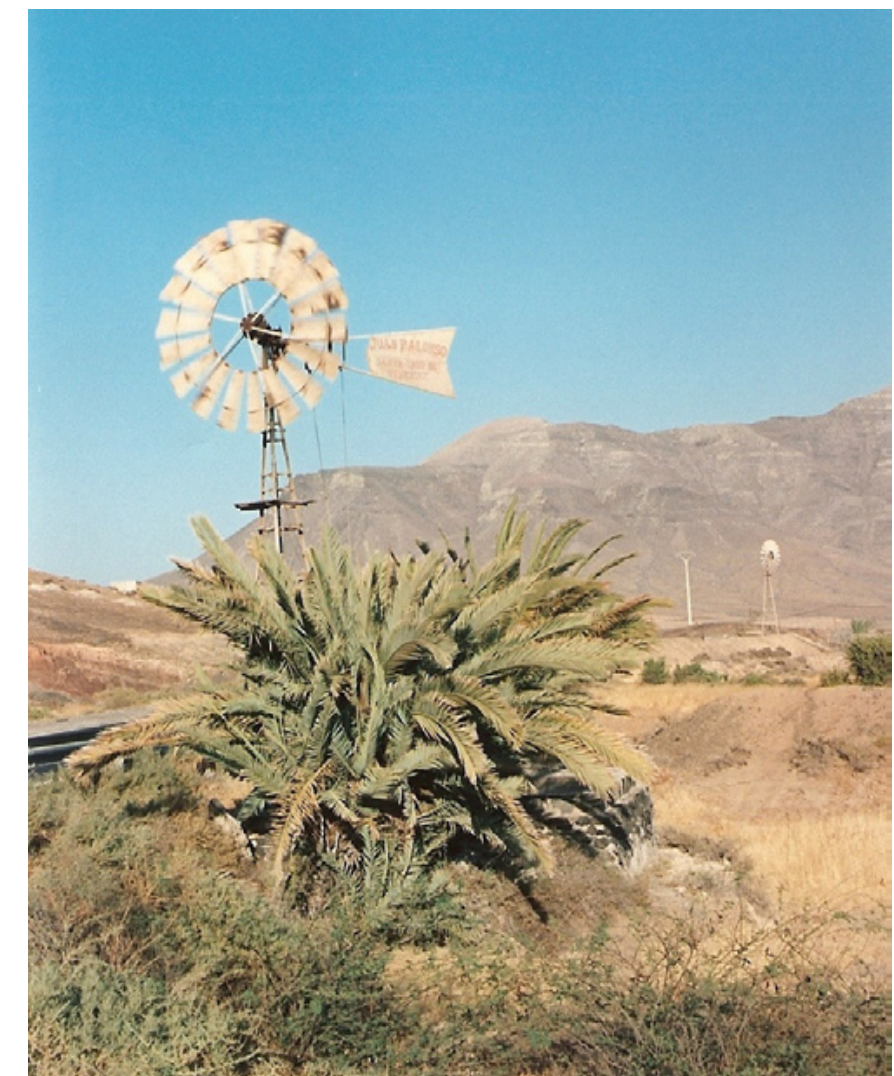

Se están recuperando los molinos y pozos tradicionales para la extracción de agua, motivado por el cese de subvención a las desalinadoras. Isla de Lanzarote | foto Victoria Batista Pérez 